\title{
Microstructure and Mechanical Properties of Ti-35Nb-7Zr-XCPP Biomaterials Fabricated by Rapid Sintering
}

\author{
Kee-Do Woo ${ }^{\dagger}$, Sang-Hoon Park, Ji-Young Kim, Sang-Mi Kim and Min-Ho Lee* \\ Dental Schoolvision of Advanced Materials Engineering, Research Center of Advanced Materials Development \\ (RCAMD), Chonbuk National University, Chonbuk 561-756, Korea \\ *Department of Dental Biomaterials, School of Dentistry, Chonbuk National University, Chonbuk 561-756, Korea
}

(Received January 19, 2012 : Received in revised form February 17, 2012 : Accepted March 1, 2012)

\begin{abstract}
Ti-6Al-4V ELI (Extra Low Interstitial) alloy have been widely used as alternative to bone due to its excellent biocompatibility, although it still has many problems such as high elastic modulus and toxicity. Therefore, biomaterials with low elastic modulus and non toxic characteristics have to be developed. A novel $\beta \mathrm{Ti}-35 \mathrm{wt} \% \mathrm{Nb}-7 \mathrm{wt} \% \mathrm{Zr}-\mathrm{Calcium}$ pyrophosphate (CPP) composite that is a biocompatible alloy without elemental $\mathrm{Al}$ or $\mathrm{V}$ was fabricated by spark plasma sintering (SPS) at $1000^{\circ} \mathrm{C}$ under $70 \mathrm{MPa}$ using high energy mechanical milled (HEMM) powder. The microstructure and phases of the milled powders and the sintered specimens were studied using SEM, TEM, and XRD. Ti-35wt $\% \mathrm{Nb}-7 \mathrm{wt} \% \mathrm{Zr}$ alloy was transformed from $\alpha$ phase to $\beta$ phase in the 4 h-milled powder by sintering. The sintered specimen using the 4 h-milled powder showed that all the elements were distributed very homogeneously and had higher density and hardness. $\beta$ Ti alloy-CPP composite, which has nanometer particles, was fabricated by SPS using HEMMed powder. During the sintering process, $\mathrm{CaTiO}_{3}$, TixOy, and $\mathrm{CaO}$ were formed because of the reaction between Ti and CPP. The Vickers hardness of the composites increases with the increase of the milling time and the addition of CPP. The biocompatibility of the Ti-Nb-Zr alloys was improved by addition of CPP.
\end{abstract}

Key words biomaterial, sintering, microstructure, calcium pyrophosphate, HEMM.

\section{Introduction}

Ti and Ti-based alloys are widely used as biomaterials due to the combination of its outstanding characteristics such as high strength, low density (high specific strength), high immunity to corrosion, complete inertness to body environment, enhanced biocompatibility, low modulus and high capacity to join with bone and other tissues. ${ }^{1,2)}$ Nowadays, pure titanium, Ti-6Al-4V ELI (extra low interstitial) alloy have been widely used as dental and orthopedic implants. ${ }^{3,4}$ However these alloys have been considered because of the toxic elements to health, such as $\mathrm{Al}$ and $\mathrm{V}$. In addition, the poor shear strength and higher elastic modulus of $\mathrm{Ti}$ and $\mathrm{Ti}$ based alloys may result in "stress shielding" and implants failure. Recently $\beta$ Ti alloys with low elastic modulus have been considered. ${ }^{5,6)}$ And the full $\beta$-phase Ti alloys have lower Young's modulus range from 60 to $80 \mathrm{GPa}^{7{ }^{7}}$ However, full $\beta$-phase Ti alloys must lead to low strength. There are two ways to strengthen the $\beta$ phase: one is alloying and the other is reducing grain size. The former may also lead to the increase in elastic modulus because the alloying must change the atom-bond

${ }^{\dagger}$ Corresponding author

E-Mail : kdwoo@jbnu.ac.kr (K. -D. Woo) of $\beta$-phase Ti alloys. Therefore, reducing grain size is the best way to strengthen the $\beta$-phase Ti alloys. Generally, when grain size is reduced into nanometer scale, the strength will significantly increase. ${ }^{8,9)}$ Recently, Ti-Nb-X alloys, such as Ti-Nb-Mo and Ti-Nb-Zr alloy.

CPP and Hydroxyapatite (HA), which has similar composition and structure to human bones, has excellent biocompatibility and combination ability with human bones. Therefore CPPand HA is a favorable candidate material for human body replacements. However, CPP has poor mechanical properties, and CPP coatings on metallic implants often flake off because of poor ceramic/ metal interface bonding, which may cause surgery to fail. This problem may be solved by synthesis of metal/CPP composites. In these years, research on Ti-based alloys/HA composites for biomedical applications is developing fast, Liu et al. and Woo et al. have studied Ti/HA bio-composites fabricated by metallurgic and sintering method. A. Inoue et al. used the HA particles as the appropriate second phase to form a bulk glassy alloy composite. But CPP added Ti based composite has not reported.

Therefore, in the present study we aims to synthesize a new biomaterial $\mathrm{Ti}-\mathrm{Nb}-\mathrm{Zr} / \mathrm{CPP}$ composite fabricated by spark plasma sintering (SPS) using different milled powders for 0.5 to $6 h$. 
In this study, Ti-Nb-Zr-CPP composites were fabricated by spark plasma sintering (SPS) using various milled powders for improving mechanical properties.

\section{Experimental Procedure}

The raw material was designed as Ti-35wt $\% \mathrm{Nb}-7 \mathrm{wt} \% \mathrm{Zr}$ $\mathrm{X} \%(5,10,20) \mathrm{wt} \% \mathrm{CPP}$, in which high pure $\mathrm{Ti}$ powders (99.9\%, 100mesh), Nb powders $(99.8 \%, 325 \mathrm{mesh}), \mathrm{Zr}$ powders $(99.8 \%, 325 \mathrm{mesh})$ and pure CPP powders (average size, $10 \mu \mathrm{m})$ were used.

Table 1 shows composition of specimens. The powders were milled in Argon atmosphere for different times (0.5 6h) using high energy mechanical ball milling. The mixed and milled powders were sintered rapidly by SPS with a $10^{-2}$ vacuum and $70 \mathrm{MPa}$ uniaxial pressure to prohibit grain growth of composite. The sintering was conducted at $1000^{\circ} \mathrm{C}$ for short time.

Fig. 1 shows shematic of SPS (Spark Plasma Sintering) equipment.

Temperature was measured using a pyrometer focused on the surface of the graphite die. The phase of Ti-NbZr-CPP composites and powders have been investigated using X-ray diffraction (XRD) with $\mathrm{CuK} \alpha$ radiation within the range of $20-80^{\circ}$. The shape of Ti-Nb-Zr-CPP powders and morphologies were observed by a scanning electron microscope (JMS-6400 : SEM). The density of Ti-Nb-Zr-

Table 1. Composition proportion of specimens (wt.\%).

\begin{tabular}{ccccc}
\hline Specimen & $\mathrm{Nb}$ & $\mathrm{Zr}$ & $\mathrm{CPP}$ & $\mathrm{Ti}$ \\
\hline 1 & 35 & 7 & - & Bal. \\
2 & 35 & 7 & 5 & Bal. \\
3 & 35 & 7 & 10 & Bal. \\
4 & 35 & 7 & 20 & Bal. \\
\hline
\end{tabular}

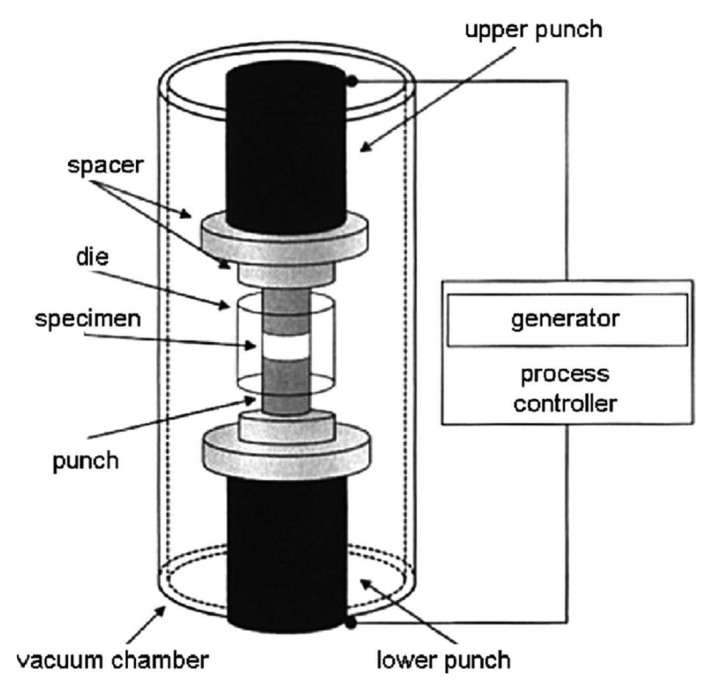

Fig. 1. Schematic of SPS (Spark Plasma Sintering).
CPP composites was calculated by Archimedes' method. The hardness was measured using Vickers hardness machine (Load: $100 \mathrm{gf}$ ). The relative density of the sintered specimens was performed by Archimedes' principle.

\section{Results and Discussion}

Fig. 2 shows scanning electron micrographs (SEM) of the as-milled powders. The powders were gradually formed composite after milling for $4 \mathrm{~h}$, and the particle size of the composite powders decreased from 10 50 $\mu \mathrm{m}$ (Fig. 2b) to less than $5 \mu \mathrm{m}$ with much finer particles (Fig. 2c). And the shape of the milled powders changed from irregular shape to round shape. In other word, the size of the $\mathrm{Ti}-35 \% \mathrm{Nb}-7 \% \mathrm{Zr}-\mathrm{X} \% \mathrm{CPP}$ powder was decreased with increasing milling time. The particle size of $4 \mathrm{~h}$ milled powder is less than $100 \mathrm{~nm}$ calculated by XRD peak. By XRD patterns of the powder fabricated by milling for $0.5 \mathrm{~h}, 1 \mathrm{~h}$ and $4 \mathrm{~h}$. The XRD patterns of the mixed powders indicated that there were only $\alpha-\mathrm{Ti}, \mathrm{Nb}, \mathrm{Zr}$ and CPP, it means there is no reaction duing the mixing and

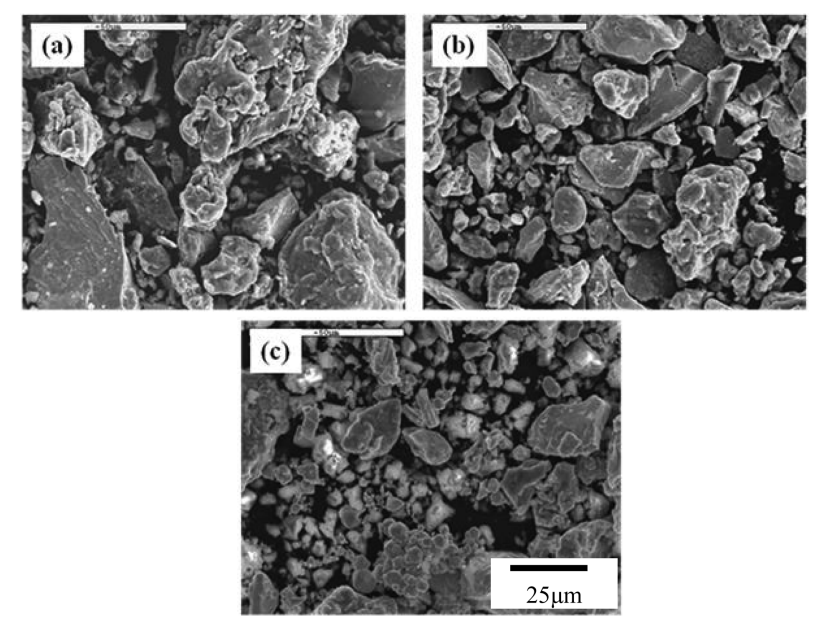

Fig. 2. SEM image of Ti-35Nb-7Zr-10CPP powders; (a) $0.5 \mathrm{~h}$ milled, (b) $1 \mathrm{~h}$ milled and (c) $4 \mathrm{~h}$ milled.

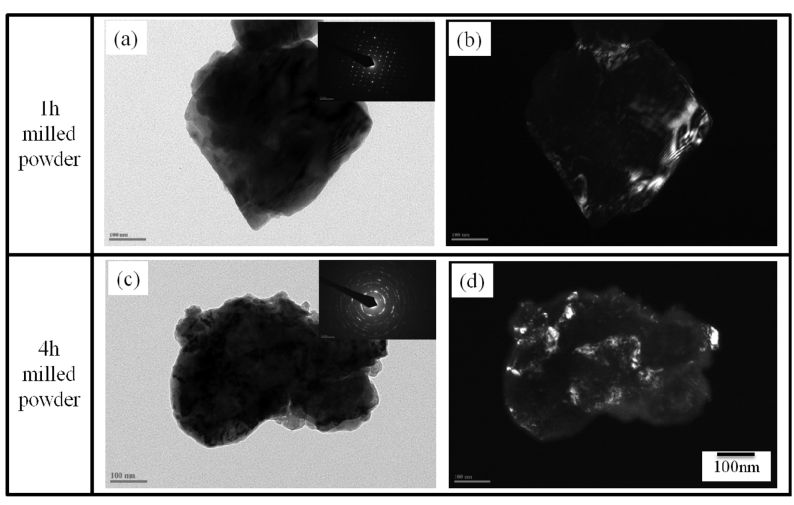

Fig. 3. TEM images (a, c) and HEMM images (b, d) of Ti-35Nb-7Zr10CPP milled powders. 
milling process for $4 \mathrm{~h}$.

Fig. 3 shows transmission electron microscope (TEM) images of the milled $1 \mathrm{~h}$ and $4 \mathrm{~h}$ powder.

While high energy mechanical milling (HEMM) is being conducted, particles agglomerated by cold welding and followed by broken by steel balls. This phenomenon such as agglomerating and smashing is continued. The selected area diffraction $(\mathrm{SAD})$ pattern of the $1 \mathrm{~h}$ milled powder shows spot pattern (Fig. 3(a)), but 4h milled powder shows ring patterns (Fig. 3(c)). Generally, The coarsening grain reveal spot pattern. In other word, the size of the Ti- $35 \% \mathrm{Nb}-7 \% \mathrm{Zr}-\mathrm{X} \% \mathrm{CPP}$ powder was decreased with increasing milling time. The particle size of 4h milled Ti-35\%Nb-7\% Zr-X\%CPP powder is about less than $100 \mathrm{~nm}$. By C. Suryanarayana and M. Grant Norton equation using XRD peak, the particle size of $6 \mathrm{~h}$ milled powder is about $60 \mathrm{~nm}^{.10)}$

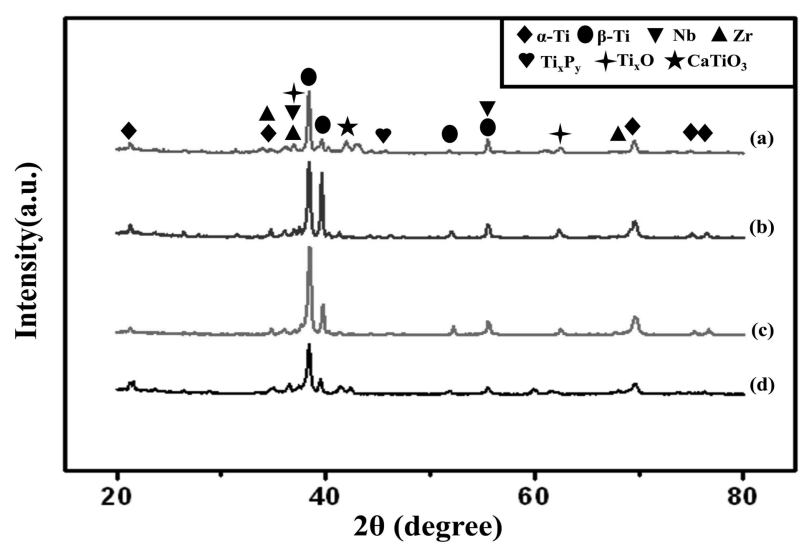

Fig. 4. XRD patterns of the sintered Ti-35Nb-7Zr composite milled for 4h; (a) Ti-35Nb-7Zr-20CPP, (b) Ti-35Nb-7Zr-10CPP, (c) Ti-35Nb$7 \mathrm{Zr}-5 \mathrm{CPP}$ and (d) Ti-35Nb-7Zr.
Fig. 4 shows the XRD patterns of SPS sintered specimens fabricated by different milled time powders respectively. The XRD curves shows that $\alpha$-Ti phase is remained in all sintered specimens, but it reduces gradually with the milling time increases, and it almost disappears in the specimen fabricated by $4 \mathrm{~h}$ milled powder, at the same time $\beta$-Ti phase forms because of $\mathrm{Nb}$ as a $\beta$ phase stabilizing alloying element to form homogenous solid solution into Ti. Iron peak did not appear due to a few contents included by milling. There are some new phases appear in sintered specimens, such as $\mathrm{CaTiO}_{3}$, $\mathrm{Ti}_{2} \mathrm{O}, \mathrm{CaO}$ and $\mathrm{Ti}_{\mathrm{x}} \mathrm{P}_{\mathrm{y}}$. These phases indicate that $\mathrm{CPP}$ would reacted with Ti during sintering process. And this reaction has been found in many Ti/HA bio-composite research, the reaction was suggested to be

$$
\mathrm{Ti}+\mathrm{Ca}_{10}\left(\mathrm{PO}_{4}\right)_{6}(\mathrm{OH}) \rightarrow \mathrm{Ti}_{2} \mathrm{O}+\mathrm{CaTiO}_{3}+\mathrm{CaO}+\mathrm{Ti}_{\mathrm{x}} \mathrm{P}_{\mathrm{y}}
$$

Fig. 5 shows effect of CPP contents on sintering ability of Ti-35\% Nb-7\% $\mathrm{Zr}$ composite. Load uniaxial pressure of $70 \mathrm{MPa}$ during sintering improved densification and decreased pore ratio. As shown in Fig. 5, ratio of pore was increased with increasing CPP contents, but was decreased with increasing milling time, and morphology of phase was more homogeneous with increasing milling time. Because fine powders affected densification and sintering ability. By this result, fabrication of CPP added Ti-35\% Nb-7\%Zr composite is very difficult due to low wetting ability between Ti alloy and ceramic of CPP even if fine particles.

Fig. 6 shows milling time effect on sintering ability of Ti-35\% Nb-7\%Zr-10\%CPP composite. By using 6 h high energy mechanical milled powder, which is nano-sized, Ti-35\%Nb-7\%Zr-10\%CPP composite can be fabricated

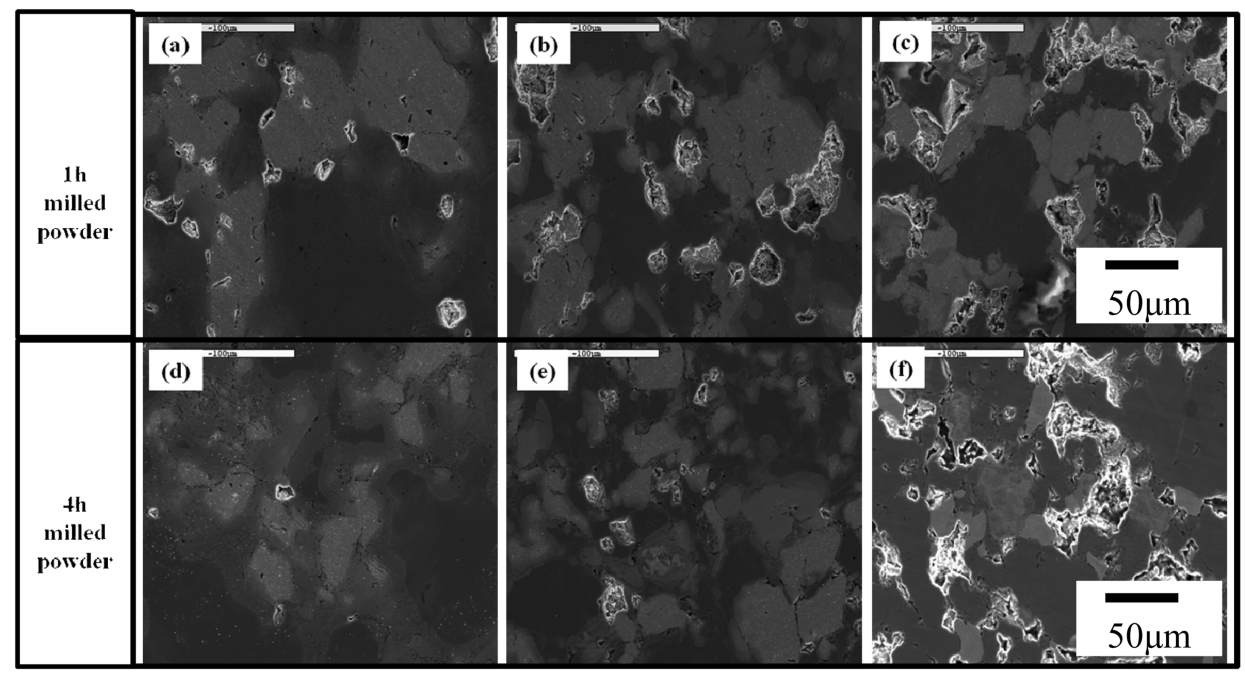

Fig. 5. SEM images of sintered Ti-Nb-Zr-CPP composites produced by HEMM and SPS; (a),(d) Ti-35Nb-7Zr-5CPP, (b),(e) Ti-35Nb-7Zr$10 \mathrm{CPP}$ and (c),(f) Ti-35Nb-7Zr-20CPP. 

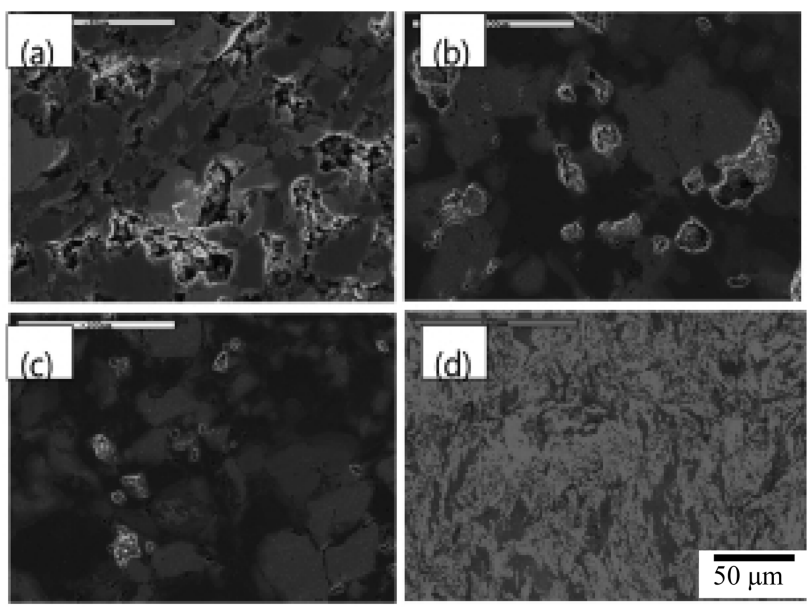

Fig. 6. SEM images of sintered Ti-35\%Nb-7\%Zr-10\%CPP specimens using mixed powder for $24 \mathrm{~h}$ and milled powder for (a) $0.5 \mathrm{~h}$, (b) $1 \mathrm{~h}$ and (c) $4 \mathrm{~h} \mathrm{(d)} 6 \mathrm{~h}$.

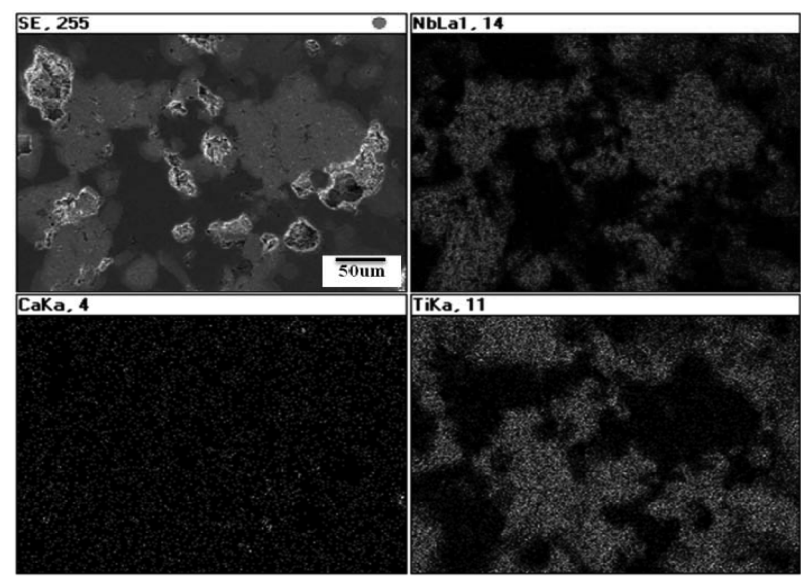

Fig. 7. (a) SEM and (b, c, d) mapping images of sintered Ti-36\% Nb$7 \% \mathrm{Zr}-20 \% \mathrm{CPP}$ powder with milled powder for $0.5 \mathrm{~h}$.

successfully. From this result, particle size is important fact to fabricate successfully ceramic included metallic composite such as Ti-35\% $\mathrm{Nb}-7 \% \mathrm{Zr}-\mathrm{X} \% \mathrm{CPP}$ biomaterials. HEMM machine is very useful tool to make nano-sized ceramic particles.

Fig. 7 shows EDX mapping images of sintered Ti$35 \% \mathrm{Nb}-7 \% \mathrm{Zr}-20 \% \mathrm{CPP}$ powder with milled powder for $0.5 \mathrm{~h}$. Form this result, white phase is consist of $\mathrm{Nb}$, but black phase is consist of Ti. Ca of CPP distributed homogeneously. $\mathrm{Ca}$ is main composition of CPP. Therefore $\mathrm{Ca}$ which distributed homogeneous will improve coating ability between HA or CPP on Ti based alloys. By result of Woo, $\mathrm{Zr}$ mainly exists on the holes. ${ }^{11)}$

Table 2 shows the relative density and hardness of sintered Ti-Nb-Zr-CPP composites using each powder. With increase milling time and CPP content, hardness was increase. However in case of increasing CPP amount, relative density was decreased. The relative density of composites having higher $\mathrm{CPP}$ content decreased due to the different thermal expansion between $\mathrm{Ti}$ alloys and ceramic of CPP. Some paper reported that hardness of the rapid sintered composite fabricated by high energy milled powder depends on the milling time, because grain size of sintered composites decreased with increasing milling time due to finer particle. And ceramic such as CPP is higher hardness it suggested that this phenomenon influenced increasing hardness.

\section{Conclusion}

In the present research, the nanometer composite material of Ti-35wt $\% \mathrm{Nb}-7 \mathrm{wt} \% \mathrm{Zr}-\mathrm{X} \% \mathrm{CPP}$ was fabricated by HEMM and SPS sintering. And the property of the milled powder and the sintered specimens were analyzed. We can conclude as following:

1) Nanometer size and homogenous Ti-35wt $\% \mathrm{Nb}-7 \mathrm{wt} \%$ $\mathrm{Zr}-\mathrm{X} \% \mathrm{CPP}$ composite powders are obtained after the pure $\mathrm{Ti}, \mathrm{Nb}, \mathrm{Zr}$ and $\mathrm{CPP}$ powders milled for $6 \mathrm{~h}$.

2) The sintered specimen by $4 \mathrm{~h}$ milled powder showed a very fine grain size microstructure and the distribution of elements was very homogenous, the grain size can be about $0.1-1 \mu \mathrm{m}$. And a $\alpha$-Ti phase transformed to $\beta-\mathrm{Ti}$ phase almost completely by sintering because of the solid

Table 2. Physical and mechanical properties of the sintered specimens.

\begin{tabular}{clcc}
\hline Time & \multicolumn{1}{c}{ Specimen } & Relative Density $(\%)$ & Hardness $\left(\mathrm{kg} / \mathrm{mm}^{2}\right)$ \\
\hline \multirow{3}{*}{ 1h-milled powder } & Ti-35\%Nb-7\%Zr-5\%CPP & 96.1 & 348.8 \\
& Ti-35\%Nb-7\%Zr-10\%CPP & 93.9 & 462.5 \\
& Ti-35\%Nb-7\%Zr-20\%CPP & 91.4 & 484.6 \\
& Ti-35\%Nb-7\%Zr-5\%CPP & 96.9 & 351.9 \\
4h-milled powder & Ti-35\%Nb-7\%Zr-10\%CPP & 93.6 & 411.1 \\
& Ti-35\%Nb-7\%Zr-20\%CPP & 92.2 & 479.2 \\
6h-milled powder & Ti-35\%Nb-7\%Zr-5\%CPP & 98.9 & 385.9 \\
& Ti-35\%Nb-7\%Zr-10\%CPP & 97.6 & 540.1 \\
& Ti-35\%Nb-7\%Zr-20\%CPP & 95.2 & 562.2 \\
\hline
\end{tabular}


solution of $\mathrm{Nb}$ in $\mathrm{Ti}$.

3) The hardness increased with the milling time. And also hardness of composites was increased with addition of CPP contents but, relative density was decresed.

\section{Acknowledgements}

This research was conducted with financial help from the "National Research Foundation (NRF) of Korea (20100016844).

\section{References}

1. M. Long and H. J. Rack, Biomaterials, 19, 1621 (1998).

2. H. S. Kim, W. Y. Kim and S. H. Lim, Scripta Mater., 54, 887 (2006).

3. E. Takahashi, T. Sakurai, S. Watanabe, N. Masahashi and S. Hanada, Mater. Trans., 43, 2978, (2002).
4. L. M. Elias, S. G. Schneider, S. Schneider, H. M. Silva and F. Malvisi, Mater. Sci. Eng., A432, 108 (2006).

5. H. S. Kim, S. H. Lim, I. D. Yeo and W. Y. Kim, Mater. Sci. Eng., A449-451, 322 (2007).

6. S. Ishiyama. S. Hanada and O. Izumi, ISIJ International, 31, 807 (1991).

7. P. Laheurte, A. Eberhardt and M. J. Philippe, Mater. Sci. Eng., A396, 223 (2005).

8. S. Nag, R. Banerjee and H. L. Fraser, Acta Biomaterialia, 3, 369 (2007).

9. Y. L. Hao, S. J. Li, S. Y. Sun and R. Yang, Mater. Sci. Eng., A441, 112 (2006).

10. H. C. Kim, I. J. Shon, J. K. Yoon and J. M. Doh, Int. J. Refrac. Met. Hard Mater., 25, 46 (2007).

11. K. D. Woo, D. S. Kang, S. H. Kim, S. H. Park, J. Y. Kim and H. R. Ko, J. Kor. Powd. Metal. Inst., 18, 188 (2011) (in Korean). 